\title{
Community-based breeding programmes are a viable solution for Ethiopian small ruminant genetic improvement but require public and private investments
}

\author{
Aynalem Haile $^{1}$ (D) ｜ Solomon Gizaw ${ }^{2} \quad$ | Tesfaye Getachew ${ }^{1} \quad$ Joaquín P. Mueller ${ }^{3}$ | \\ Peter Amer $^{4}$ | Mourad Rekik ${ }^{5}$ | Barbara Rischkowsky ${ }^{1}$
}

${ }^{1}$ ICARDA, Addis Ababa, Ethiopia

${ }^{2}$ ILRI, Addis Ababa, Ethiopia

${ }^{3}$ National Institute for Agricultural

Technology (INTA), Bariloche, Argentina

${ }^{4}$ AbacusBio Limited, Dunedin, New

Zealand

${ }^{5}$ ICARDA, Amman, Jordan

\section{Correspondence}

Aynalem Haile, ICARDA, P.O. Box 5689,

Addis Ababa, Ethiopia.

Email: a.haile@cgiar.org

Funding information

CGIAR CRP Livestock genetics flagship

\begin{abstract}
Ethiopia has a large and diverse population of small ruminants, which contribute substantially to the livelihood and income of the rural poor and the country at large. However, the sector faces a number of challenges. Productivity per animal and flock offtake are both very low. Reasons attributed for the apparent low productivity are as follows: absence of appropriate breeding programmes, lack of technical capacity, inadequate and poor-quality feeds, diseases leading to high lamb mortality, and underdeveloped markets in terms of infrastructure and information. Historically, sheep and goats have received little policy or investment attention. Genetic improvement of small ruminants could contribute to bridging the productivity gap. In the past, the government of Ethiopia has placed much emphasis on importing exotic genetics and cross-breeding with local stock as a strategy for genetic improvement. However, this has not led to a significant productivity improvement and the programmes have generally been unsustainable. Currently, there is a change in approach and a recognition of the need to focus genetic improvement efforts on the local genetic resources that are well adapted to the diverse agro-ecologies and production environments in the country. Community-based breeding programmes (CBBPs), which focus on indigenous stock and consider farmers' needs, views, decisions and active participation, from inception through to implementation, have been identified as programmes of choice. The Ethiopian government and the private sector need to invest in strategic areas around CBBPs to make the programme work for the poor and be sustainable in low-input systems.
\end{abstract}

K E Y W O R D S

breeding strategies, productivity challenges, sheep and goats

\section{1 | INTRODUCTION}

In Ethiopia, sheep and goats are mostly kept by smallholders and the rural poor, including women-headed households. The sheep and goat populations are estimated at 30.7 and 30.2 million, respectively (CSA, 2017). These species contribute substantially to the livelihoods of smallholder households as a source of income, food and raw materials (wool, skins). They also serve as a means of risk mitigation during crop failures, savings and 
investments in addition to other socio-economic and cultural functions.

Agriculture provides sustenance for more than $80 \%$ of the population and accounts for $34.9 \%$ of GDP and $83.9 \%$ of total exports (NBE, 2018). Based on 2017/18 data, the livestock sector contributes up to $25.6 \%$ of agricultural GDP and $10.5 \%$ of total Ethiopian foreign exchange earnings (NBE, 2018). The high stock numbers, however, are not leading to higher exports or export earnings for live animals or meat. Ethiopia's annual exports of cattle and sheep meat were valued at USD 79.13 million in 2012 (ECRA, 2012), while Botswana with a much lower stock number was able to reach USD 150 million export earnings from beef alone (FAO, 2012). The lower export level in Ethiopia could possibly be attributed to stronger local demand leading to higher prices, relatively lower meat output and differences in efficiency of meat production systems.

Sheep meat production grew by $2 \%$ per year on average between 2005 and 2011 but has been relatively unstable. From $68,000 \mathrm{t}$ in 2005, production reached $85,000 \mathrm{t}$ in 2011 , except in 2008 when it decreased by $4.2 \%$ compared to 2007 . It recovered in 2009 and has been growing since (Legese \& Fadiga, 2014). The average annual growth rate in sheep meat production was expected to be at $6 \%$ between 2013 and 2016 to keep up with a rise in sheep meat consumption and exports. For goat meat, low carcass yield in 2007 and 2008 led to a low production level. Goat meat production grew by an average of $2 \%$ per year between 2005 and 2011, reaching $51,000 \mathrm{t}$ in 2011. Carcass yield is expected to revert to its historical levels, hovering around $8.4 \mathrm{~kg} / \mathrm{animal}$. Thus, goat meat production was expected to grow annually by $4 \%$ on average for the 2012-2016 period, reaching 61,000 t in 2016 because of strong demand for goat meat in the domestic and export markets (Legese \& Fadiga, 2014).

The small ruminant industry in Ethiopia contributes substantially to the livelihood of the rural poor and the country at large but is faced with various challenges. Productivity per animal and flock offtake are low. For example, estimates of the average annual offtake rate from sheep and goat flocks for the years 2008-2010 indicate values between 30\% and $38 \%$ (Legese \& Fadiga, 2014). Productivity is low for a range of reasons: high kid/lamb mortality, low growth rates, poor nutritional status resulting in infertility and long kidding intervals and disease prevalence. Controlled breeding is rare, and there is limited culling of poorly performing does and breeding males.

Genetic improvement of the small ruminants could contribute to tackling the challenges the sector faces. However, the attention given to research and development investment in the sector is very minimal. To date, the investments made in genetic improvement have generally focused on importation of exotic germplasm and cross-breeding with the local stock, which were generally unsustainable and expensive failures.
The Government of Ethiopia recognizes the need for change in approach, and community-based breeding programmes (CBBPs; Mueller et al., 2015) have now been identified as the strategy of choice. This paper highlights approaches in genetic improvement of small ruminants, pinpoints major challenges in breeding programmes and identifies areas where investment is required to ensure sustainability of CBBPs in Ethiopia.

\section{SMALL RUMINANT BREEDING PROGRAMMES IN ETHIOPIA}

The approaches used to date for small ruminant breeding programmes in Ethiopia are three:

- cross-breeding and distribution of cross-breed rams from stations/ ranches

- selective breeding involving central nucleus schemes

- community-based breeding programmes.

The small ruminant breeding strategies adopted in Ethiopia over the last few decades largely focused on importing exotic breeds for cross-breeding, and since the early 1960s, substantial efforts have been made (Tibbo, 2006). These have included importing exotic sheep breeds such as Bleu du Maine, Merino, Rambouillet, Romney, Hampshire, Corriedale, Dorper and Awassi sheep, and Saanen, AngloNubian, Toggenburg and Boer goats. Different government (research organizations and universities), non-government institutions (e.g., FARM AFRICA) and projects (e.g., Chilalo Agricultural Development Unit and Ethiopia Sheep and Goat Productivity Improvement Program) implemented these introductions and cross-breeding. However, these genetic improvement programmes produced no significant effects on sheep and goat productivity or on farmers' and pastoralists' livelihoods and the national economy at large (Tibbo, 2006).

The major limitation faced by livestock cross-breeding programmes in Ethiopia has been the lack of a clear and documented breeding and distribution strategy. There has been very little consideration of the needs of the farmers and pastoralists, their perceptions and indigenous practices. Additionally, they have had limited or no participation in the design and implementation of the breeding programmes, leading to low commitment. Furthermore, the breeding programmes lacked breeding schemes to sustain cross-breeding at the nucleus centres and at the village level (Gizaw, Komen, $\&$ Arendonk, 2010). The distribution of the improved genotypes of these programmes was indiscriminate and unplanned, resulting in failure of the breeding programmes and threatened to dilute the sheep and goat genetic diversity in the country. 
The indigenous small ruminant genetic resources of Ethiopia have high within-breed genetic variation (Abegaz, 2002; Kebede, Haile, Dadi, \& Alemu, 2012) and desirable characteristics. However, there has been little effort to improve their genetic merit using within-breed genetic selection. The few sheep selective breeding programmes initiated by the Institute of Agricultural Research in the 1980s, which included both Afar and Horro sheep, were limited to the formation of elite nucleus flocks and the programmes have since been discontinued. There was no distribution scheme in place for the improved genotypes in the nucleus centres.

Currently, community-based breeding programmes focusing on local genotypes are being advocated as the strategy of choice for genetic improvement of small ruminants (Haile et al., 2011; Kosgey \& Okeyo, 2007; Sölkner, Nakimbigwe, $\&$ Valle-Zarate, 1998). There are breeding programmes underway for Menz, Horro, Bonga, Washera, Doyogena and Atsbi sheep and for Konso, Arsi and Abergelle local goats. Furthermore, a number of studies have been conducted to design suitable CBBPs for implementing selective breeding in smallholder farming systems in Ethiopia (Gizaw, Komen, \& Arendonk, 2009; Haile et al., 2011).

Breeding programmes in Ethiopia are mainly funded either through government and/or through short-term development projects. There has generally been very little investment in the area of small ruminant breeding programmes in Ethiopia. The little investment made during the last few decades has been used in the establishment of centralized breeding programmes mainly for cross-breeding. Private sector investment in small ruminant breeding is very limited. An example is the Yezerber sheep production and agro-processing farm in central Ethiopia which envisages the establishment of a sheep breeding farm and agro-processing plant with a capacity to accommodate around 4,000 head of animals per annum. Other less specialized programmes also exist in the North West, for example in the Metema area.

\section{3 | MAJOR CHALLENGES IN BREEDING PROGRAMMES}

Small ruminant breeding programmes in Ethiopia have had minimal meaningful impact. Some of the challenges faced are highlighted below.

\section{1 | Institutional issues}

There is a lack of clear breeding strategies appropriate for different situations. The focus has often been on the unsuccessful central nucleus schemes. There has been no clear institutional arrangement for conservation, genetic improvement and sustainable use of the small ruminant genetic resource in Ethiopia. Roles and responsibilities of the different institutions engaged in genetic improvement of small ruminants were not clearly set, and this created an overlapping effort on the same tasks among National Agricultural Research Systems, Institute of Biodiversity, Ministry of Agriculture, CGIAR, and NGO's (Gizaw, Abegaz, Abebe, Muluneh, \& Tesfay, 2018).

Research and development strategies and breeding programmes are not coordinated. Efforts of national research and development institutions, universities and international development partners are in some cases not coordinated, even when working on the same topic/breed/breeding objective. A National Animal Genetic Improvement Institution has recently (2018) been established, and a valuable early contribution from this institution would be to improve the level of coordination across programmes.

\section{2 | Project-based genetic improvement initiatives}

Genetic improvement should be seen as a long-term investment and requires a long-term vision and commitment. Nonetheless, most of the genetic improvement initiatives in Ethiopia are project-based. Donor-supported projects launched in the country tend to perform very well during the projects' life but are usually abandoned when the projects are phased out and donor support is terminated. Several cross-breeding projects involving Dorper and Boer goats are a case in point. There has been poor transition of NGO-supported genetic improvement projects into ongoing sustainable breeding programmes because of a lack of involvement and support by the public sector of Ethiopia.

\section{3 | Inefficient delivery of improved genetics}

Genetic improvement achieved in centralized breeding programmes requires that dissemination structures deliver benefits of a meaningful scale. However, inefficient genotype multiplication and distribution has been a major challenge hampering the effectiveness of breeding programmes, particularly crossbreeding programmes. Performance of cattle and sheep genotype multiplication centres is far below the demand and below expectations given the huge investment in the centres. A methodological framework for dissemination of improved genetics from CBBPs has been developed (Mueller, Rischkowsky, Haile, Getachew, \& Mourad, 2017) and is described in more detail later in the "Upscaling of CBBPs" section.

\section{4 | Limited technical capacity at different levels}

Capacity to design and implement breeding programmes is limited in Ethiopia. Capacities of all value chain actors need to be developed. For example, the breeding programme should 
be preceded by several years of extension work to train the farmers and boost their experiences and skills in small ruminant production techniques (Yapi-Gnoare, 2000). During that period, farmers should be made aware of the long-term benefits they could derive from breeding programmes including benefits from the recording activity. As can be observed, investment by the public sector is mainly in infrastructure and breeding materials (local and imported flocks). Very minimal investment in expertise has contributed to low efficiency and in some cases failure of breeding programmes and absence of science-based genetic improvement practices (Gizaw et al., 2018).

\section{5 | Absence/lack of investment by the public and private sectors}

Breeding programmes are seen as long-term investment plans, and therefore because of governments' needs for immediate results, there is generally little investment compared with investment in alternative interventions. Additionally, almost all of the modest investments made in genetic improvement have come from the public sector. There is virtually no investment by the private commercial sector and very minimal investment by smallholders and pastoralists. It is clear that within-breed selection schemes will result in genetic improvement, improved productivity and profitability. However, it should be noted that short to perhaps medium returns on investment will most likely come from non-genetic gains, such as improvement in feeding, disease control and better reproductive management, for example, making breeding sires available to the required number will result in more lambs immediately. Therefore, genetic improvement effort should be seen as part of an overall livestock development agenda and should consider the whole value chain. A recent cost/benefit analysis (S. Gizaw, S. Abegaz, A. Abebe, D. Muluneh \& Z. Tesfay, unpublished data) shows that there are benefits of investing in CBBP and a growing awareness of this in government is leading to accelerated investment in CBBPs.

\section{6 | Limited application of modern biotechnology tools}

Genetic improvement can potentially be accelerated through application of modern technological interventions. Limited genomic and biotechnology research and development along with a tendency for most of the research on genomics in Ethiopian small ruminants to be targeted on genetic resource characterization and evolutionary genetics have stifled any application to small ruminant genotype multiplication and genetic improvement (Gizaw S., S. Abegaz, A. Abebe, D. Muluneh, Z. Tesfay 2018). Community-based breeding programmes have great potential for testing the practical application of biotechnological tools as large numbers of recorded animals can be made available.

\section{7 | Participation in the breeding programmes}

Breeding programmes have thus far focused on centralized breeding schemes, entirely managed and controlled by governments-with minimal, if any, participation by farmers. These centralized schemes were usually run by a governmental organization attempting to undertake all or part of the complex processes and breeding strategy roles (i.e., data recording, genetic evaluation, selection, distribution of genetically improved animals and communication/extension to farmers). These schemes failed to sustainably provide the desired genetic improvements, continuous provision of a sufficient number and quality of improved breeding males to smallholders, and also failed to engage the key end-users in the process. Community-based breeding programme described below in detail is suggested as alternatives.

\section{8 | Monitoring and evaluation}

There have been several initiatives on genetic improvement for small ruminants in Ethiopia. Genetic progress (the ultimate milestone of genetic improvement programmes) and socio-economic benefits have not been monitored and reported for most selection programmes. Our reports (Gutu et al., 2015; Haile et al., 2017) on Ethiopian CBBP briefly described under the "Results from CBBP" section could contribute to averting such limitations. Absence of pre-evaluation of genetic and bio-economic feasibility of breeding programmes are some gaps discovered (Gizaw et al., 2018).

\section{COMMUNITY-BASED BREEDING PROGRAMMES}

Breeding programmes described as community based cover a range of situations (e.g., Haile et al., 2011; ICARFAO, 2000; Sölkner et al., 1998) but typically target lowinput systems with farmers within limited geographical boundaries having a common interest to work together for improvement of their genetic resources (Mueller et al., 2015). Community-based breeding programmes focus on indigenous stock and consider farmers' needs, views, decisions and active participation, from inception through to implementation, and therefore provide a participatory and bottom-up approach. Ethiopian CBPP combines selection of breeding rams/bucks based on careful recording of important production parameters, such as body weight at 6 months and ewe/doe lambing/kidding interval, with expert local opinion as to what constitutes a good ram/buck 
and communal use of selected rams/bucks. Farmers who wish to participate are organized into sheep/goat breeding associations, many of which later evolve into formal cooperatives (Haile et al., 2011). Local enumerators are recruited to help in data collection, which is then managed in a database and analysed by scientists from local research centres to help to inform selection decisions.

The whole community flock is treated as one, and two stages of ram/buck selection are usually applied: initial screening when traditionally premature sales of young lambs/kids occur (at 4-6 months of age) and final selection for admission to breeding. All young rams/bucks are collected at one central place in each community on an agreed screening date. Selection is then carried out based on the estimated breeding values, and index is constructed where more than one trait is involved.

A breeding ram selection committee composed of about 3-5 members elected by the community are involved in the selection. If, for example, 15 rams/bucks were to be selected from 100 candidates, 20 would be preselected based on their breeding values, and the committee ranks the selected rams/ bucks culling the last five. The committee checks on the conformation, coat colour, presence or absence of horns, horn type, tail type and other criteria in decision making. The number of rams/bucks to be selected depends on the number of ewes/does available for mating with a male to female allocation ratio of $1 \mathrm{ram} / \mathrm{buck}$ to 30 ewes/does while accounting for the replacement rate required.

In Ethiopia, the pilot CBBPs are designed and implemented since 2010 by a team of researchers from the International Center for Agricultural Research in the Dry Areas and International Livestock Research Institute, BOKU University, Austria and Ethiopian National Agricultural Research Centers. These programmes were supported through various projects with financial support from different donors. The day-to-day follow-up of these programmes was done by the research and extension departments of the Ethiopian government.

The Ethiopian Government has accepted CBBP as the strategy of choice for genetic improvement of small ruminants as explicitly indicated in the Ethiopian Livestock Master Plan (Shapiro et al., 2015). Consequently, the second "Growth and Transformation Plan of the Ethiopian Government" and the new World Bank Livestock and Fisheries sector development projects are adopting CBBP. The strategy of upscaling by the Government focuses on using the existing CBBPs as nucleus stock where genetic improvement is generated and disseminated.

\section{5 | RESULTS FROM CBBP}

Community-based breeding programmes have been established in a few countries around the globe but mainly as pilot projects. In Ethiopia, there are around $40 \mathrm{CBBPs}$ each having around 80 households. As CBBP is a relatively new strategy for genetic improvement of small ruminants, the last few years have been spent on testing the functionality of the strategy and we have been refining and customizing the programme to different agro-ecologies and production systems. We evaluated both biological and socio-economic performance of three CBBPs in Ethiopia, and some of the results include the following (Gutu et al., 2015; Haile et al., 2017):

- Sheep/goat farming, once a side activity for these farmers, is now their main business activity and the linchpin of their livelihoods.

- The best rams/bucks are now retained in the community for breeding instead of being sold for slaughter.

- High demand for breeding rams from neighbouring communities, other government programmes and NGOs in all sites, provides the base for specific business models around production of breeding sires and semen for artificial insemination.

- 3,200 households with more than 19,200 people in 40 villages directly benefiting from the scheme.

- Most of the participating households in Menz (one of the CBBP sites) graduated from the government-run safety net programme that meets short-term food needs through emergency relief. They now use income from sheep sales to buy food.

- "Best of stock" growing breeding lambs/kids, previously sold and slaughtered ("negative selection"), are now kept improving the breeding stock.

- More than 35 functional cooperatives established.

- Increased income from sheep production (since CBBP inception in 2010, an average increase of 20\%) and increased mutton consumption (now an average of three sheep slaughtered for home consumption per family per year compared to one sheep at the project start) directly linked to CBBP production in Bonga, Horro and Menz.

- Farmers' sheep/goats have shown an improvement in performance, such as lamb growth rate, lambing interval, reduced mortality and tend to attract higher prices in markets compared to sheep/goats from farmers who are not members of breeding groups.

- Most of the established cooperatives have been able to build capital (e.g., Boka-Shuta cooperative has capital of about USD 60,000).

\section{6 | UPSCALING OF CBBP}

Several pilot CBBPs have been implemented in Ethiopia since 2010. Looking at the benefits and practical feasibility of CBBP (Gutu et al., 2015; Haile et al., 2017), the 
government of Ethiopia through its regional research and extension system (with ICARDA's support) is investing in establishment of additional CBBPs. Having now become a programme of choice, the Government of Ethiopia has decided to adopt CBBP for small ruminant genetic improvement. In Ethiopia alone, the number of CBBPs has increased from the initial six to more than 40 . However, to make impact at scale CBBPs need to cover a much larger population and area. Improved genetics produced in the CBBPs also need to be disseminated to a wider area through either natural mating or reproductive biotechnologies like artificial insemination.

Current CBBPs are primarily designed for improved rams/ bucks to contribute genetic gain in the local community small ruminant populations. While some additional young breeding males are produced and sold externally, the total number is substantially less than the number required to serve the whole target populations of each breed. Mueller et al. (2017) developed a methodological framework for up-/outscaling options of CBBP. Following a detailed computation of the different population parameters, for example in Menz, one of our CBBP sites where ICARDA and partners have established 5 CBBPs, 40 young rams (5 CBBPs $\times 8$ ram replacements per $\mathrm{CBBP}$ ) are needed yearly to replace old ones and there are $5 \times 40=200$ young rams available. Yet, a total of 2,841 young rams are needed for replacement in the whole Menz target population. Thus, only $7 \%$ of currently needed young rams are produced by the five Menz CBBPs (200/2841). The challenge of any population wide breeding programme is to increase these proportions or otherwise consider a less ambitious programme with smaller targeted core population sizes.

As indicated in Mueller et al. (2017), there are three strategies to increase the availability of improved rams/bucks: increase the number of CBBPs, increase the supply of improved rams/bucks per CBBP and increase the use of improved rams/bucks.

- Increasing the number of CBBPs requires additional project staff for recording and extension work, additional identification and weighing supplies, larger coordination and supervision efforts.

- Increasing the number of rams/bucks supplied per CBBP requires participating farmers to enhance reproduction, recording and maintaining a higher proportion of male progeny till final selection. The supply can also be increased by reducing the requirements for a ram/buck to qualify for breeding. In the latter case, this is achieved at the cost of a reduced selection differential.

- Increasing the use of improved rams/bucks through higher dissemination or through extending their use in time. Higher dissemination is possible through artificial insemination (AI). Increasing the age of ram/buck disposal also leads to higher dissemination, although at the cost of an increased generation interval.
These avenues to reach a larger sheep/goat population with improved rams/bucks are not exclusive and should be considered jointly when planning different programmes.

Community-based breeding programme has attracted global interests and is also being scaled out in many places in Africa (e.g., Malawi, Uganda, Sudan, Tanzania, South Africa) and elsewhere (Brazil, Iran, Mongolia). This was made possible because of the following reasons:

- The technology is easy to implement in local communities.

- Requires little funding compared to centralized nucleus schemes.

- The technology develops confidence in local communities as it is based on existing management and breeding practices and there is not much change that comes with it.

- Because of failure of earlier centralized schemes, people are desperate for a new approach.

\section{HOW CBBPS COULD BE MADE SUSTAINABLE}

Ideally, sustainable breeding programmes:

- meet breeding objectives of individuals, communities and nations for which they were established;

- are self-sufficient (technically, economically and socially); - are environmentally friendly (locally and globally).

An evaluation of Ethiopian sheep breeding programmes suggests that sustainability largely depends on effective and well-functioning breeder cooperatives (Gutu et al., 2015). Strengthening the financial capacity of cooperatives by linking them to better markets can contribute to the sustainability of these community-based approaches. Tailored training on financial and technical management of breeding programmes can also form part of support offered to cooperatives.

Although cooperatives and associations can build strong institutional (and financial) capacity in the short run, they cannot be expected to run breeding programmes without technical support from research and extension (Gutu et al., 2015). Continuous technical and institutional support to cooperatives from national research and extension is crucial to their sustainability. One of the major areas where CBBP cooperatives need to be supported is in data entry and processing. The local or partnering research institution can play this role. Once the database is developed and in place, the database can be updated on a near real-time basis through innovative use of aids such as cell phones and verified via the same devices. Centralized data management tools facilitate easy data capture, analysis and reporting. Simple indices based on the set selection criteria for each breed should be developed, and the overall merit values 
computed and shared with the communities and farmers as part of the feedback and for use to effect selection.

In partnership with EMBRAPA Goats and sheep (Brazil), ICARDA and its partners developed a Data Recording and Management System (DREMS), which enables the recording, storage and management of information generated in flocks of goats and sheep. This system can be made available to those who wish to use it in their CBBPs. One of the major challenges in use of DREMS is the need for reliable Internet connection, which is difficult to get in most African rural villages. To tackle this challenge, an offline application "AniCloud" is being developed by AbacusBio limited from New Zealand. This app is being tested and will be made available when it is ready.

Institutional support could also assist in ensuring sustainability of breeding programmes. However, breeding programmes initiated in Ethiopia have generally not been coordinated. Each institute undertakes its own breeding programme, and therefore, even breeding programmes on the same breed could be implemented through different institutions. One umbrella institute, for Ethiopia, for example, National Animal Genetic Resources Improvement Institute, could be mandated with coordination of all genetic improvement programmes. There could be a forum for joint planning and implementation of different activities with clear responsibility and accountability.

Community-based breeding programmes usually work with locally adapted animals, and therefore, the issue of environmental sustainability is embodied in the programmes. For animals, particularly those introduced into new environments, to cope with the changing environment there are two adaptation options: to change the environment to suit animal production and/or improve adaptation traits in livestock. Breeding programmes will not be able to improve adaptation traits in exotic breeds fast enough to keep pace with climate change. The better alternative is to focus on improving production traits in indigenous breeds. The focus in CBBPs is on indigenous breeds which are likely to cope better with climate change than exotic breeds, because they are already adapted to harsh conditions (Tibbo, Iñiguez, \& Rischkowsky, 2008). CBBPs could therefore contribute to averting the perceived negative effects of livestock on the environment, because small ruminants typically eat low-quality grazed forages and crop residues. Exotic genotypes will likely require higher quality feeds, potentially diverted from human consumption, in order to perform close to their genetic potential and most likely to even survive.

\section{COSTS AND BENEFITS IN CBBPS}

Community-based breeding programmes, through selection of offspring most likely to be genetically superior leading to continuous genetic improvement, are designed to gradually develop best performing animals in a given small ruminant population. Any public and/or private investment in CBBPs will have costs and benefits as follows.

\subsection{Costs in CBBP}

\subsection{1 | Ram/buck}

The CBBP cooperatives purchase young breeding rams from participating communities. The selected rams are used communally and are rotated among the breeding ram groups during the service period. The community members keep the breeding rams. When they complete service, in most cases after two years of service, they are either sold as breeding animals to other farmers in other areas or are fattened and sold for slaughter. When the rams are sold, half of the profit is paid to the member who kept the rams, and the remaining is the profit of the cooperative. At the initial establishment phase, the poor communities need support from the government or projects a start-up capital to purchase breeding sires which could be used as revolving fund. However, as the cooperatives are strengthened, they should be able to buy and use their breeding sires.

\subsection{2 | Veterinary service}

If there were any health-related problems in the CBBP, veterinary service could be provided. Animals are also vaccinated for known diseases. The costs for the services could be shared at the initial stage. Demand for veterinary service needs to be created, and the farmers need to see that these services in fact are beneficial. Once this is demonstrated, farmers would be prepared to cover veterinary costs.

\subsection{3 | Personnel costs}

Payment is made to the enumerators who keep the breeding records and oversee the breeding activity on the ground. Additionally, for data analysis, feedback and maintenance of database there is cost involved. These costs could be covered by government research/ extension system.

\subsection{4 | Supplies}

Ear tags and their applicators, markers, weighing scales, recording note books, pens, measuring tapes and IT-equipment for database maintenance are all needed for animal identification, data recording and management. These supplies could be provided by the government or projects when CBBPs start. However, ultimately these costs should be covered by the cooperatives when the benefits of identification and recording are demonstrated. 


\subsection{5 | Training}

The community members need to be continuously given training on the CBBP operations and on management/use of their rams/bucks/ flock and husbandry practices. This could be done by the researchers from the national system.

\subsection{6 | Feed}

The approach in CBBP is to follow the traditional animal husbandry practices of the farmers and improve their stock. Obviously, feed is one of the major costs in animal production; however, in CBBP the bulk of the feed comes from natural grazing which is difficult to quantify and not so expensive.

\section{2 | Benefits from CBBP}

The main source of income for the CBBP cooperatives is from sale of breeding rams/bucks and slaughter animals. Improvement achieved in the selection traits in the breeding programme translates to tangible benefits. If, for example, growth performance (6 months weight) and twinning rate are the selection criteria in the CBBP, then an increase in the 6month weight (in kg/year) multiplied by number of animals (ram/buck, ewe/doe) in the community multiplied by average price per $\mathrm{kg}$ would give the economic benefit from genetic improvement. Increase in twinning rate multiplied by number of lambs multiplied by survival rate multiplied by price at specific age, with the assumption of no additional cost to the household, is an easily calculated proxy of the benefit to the community.

Additionally, there are other non-genetic benefits obtained by producers. Animals from CBBP fetch better prices than non-participants in the market because buyers believe that animals in CBBP are managed well and are disease free. There is always a price margin for animals of the same weight and condition when they are from a CBBP flock or herd.

With the above costs and benefits, we evaluated profitability of three sheep CBBPs in Ethiopia and the results point to a substantial benefit to producers (S. Gizaw, S. Abegaz, A. Abebe, D. Muluneh \& Z. Tesfay, unpublished). The implication of this is that private sector investment in CBBPs could potentially be financially rewarding. Government incentives such as providing land at subsidized prices and withholding tax during initial establishment years would further encourage investment and uptake of CBBPs which should be able to become long term and self-sustaining.

Recent analyses of the genetic progress and economic benefit of sheep CBBPs out- and upscaling strategies in Ethiopia indicate that genetic progress and economic impact due to selection for weaning weight are favourable for strategies aiming at replicating current CBBPs, strategies increasing the number of rams reaching general flocks and strategies increasing the use of CBBP produced males. Return to investment replicating current CBBPs resulted in 5.1 USD per 1 USD invested. Increasing the dissemination of currently produced males in a CBBP during 20 years would generate an income to general flocks $(6,000$ ewes belonging to 600 households in six villages) of about a quarter of a million USD. Increasing the number of rams through AI can further increase genetic progress and economic income (Mueller, Rischkowsky, Haile, Getachew, \& Mourad, 2018).

At national level, benefits from CBBP include, among others, (a) Job creation for different value chain actors in the society, including women and youth; (b) Increase in productivity and income of the communities ultimately contributing to food security and livelihood improvement at national level; (c) Increased productivity and offtake rates leading to reduced prices of animal source food, hence an opportunity for consumption of animal protein that would reduce malnutrition and stunted growth; and (d) Support the national economy through export of live animals and meat. These benefits would encourage government to invest in CBBPs.

\section{9 | INVESTMENTS REQUIRED IN CBBP TO ENSURE LONG-TERM SUSTAINABILITY}

The Ethiopian government has been investing in genetic improvement of small ruminants, though not to the same extent of investment as made in other livestock species. Required investment in CBBPs is much less than what was required for other strategies, for example centralized nucleus schemes. Nevertheless, there are some priority areas where government investment is needed:

- CBBPs require establishment of an association, and we have found that legal cooperatives are necessities for sustainability of CBBPs (Gutu et al., 2015). Therefore, establishment and upskilling of breeder cooperatives in the area of business management, genetic evaluation, and husbandry practices is extremely important.

- Proper animal identification, data recording and management are crucial for CBBPs and for any breeding programme for that matter. Enumerators could be employed with support from government who could assist in this exercise until the cooperatives become self-sufficient.

- Livestock breeders are in short supply in Ethiopia. Government needs to invest in capacity development of breeders at multiple levels (for example at MSc and $\mathrm{PhD}$ levels). The current initiative, with support from the Bill and Melinda Gates foundation that plans to train young 
Ethiopians at MSc level, could contribute substantially to developing the sector.

- For dissemination of improved genetics and reproductive management, cheap, easily accessible and simple to use reproductive technologies need to be available. Successful development of the capacity for mass synchronization and AI in small ruminants could have a large impact on the ability to disseminate and upscale the benefits from existing CBBPs.

- Investment in infrastructure should be the responsibility of government. Development of handling yards for animals in cooperatives could be one example.

- There must be smooth coordination of activities among the different regional states and the federal government to avoid duplication of efforts and wise use of genetic resources.

- Transforming subsistence sheep and goat production to become market-oriented businesses is crucial. Therefore, government and private sector support in linking breeders' cooperatives to input supply, breeding animal multiplication and dissemination as well as markets is needed.

- The private sector, including farmer cooperatives, veterinary drug suppliers, feed processors and traders, could play role in provision of inputs and services to support breeding programmes. As the private sector is not well developed and is business oriented andinvestment in breeding programmes may not result in lucrative immediate benefits, incentives by government are needed. Government incentive could include, for example, tax exemption on inputs for specific period, access to credit facilities, and access to land.

\section{$10 \mid$ CONCLUSION}

Small ruminant breeding programme development is underway in Ethiopia. Breeding programmes that involve producers have proved to be technically feasible, financially rewarding and have become the choice of the Ethiopian government interventions in the livestock sector. Investment by the public and private sectors in small ruminant breeding programmes so far has been minimal, and therefore, this is an area that needs investment attention. It is recommended that the government invests in CBBPs as opposed to the oftenunsuccessful centralized nucleus schemes involving crossbreeding with exotic breeds. Incentives by governments for private sector investment in CBBPs could result in sustainable and yet rewarding benefit to all actors in the small ruminant value chain.

\section{ORCID}

Aynalem Haile (iD https://orcid.org/0000-0001-5914-0487

\section{REFERENCES}

Abegaz, S. (2002). Genetic evaluation of production, reproduction and survival in a flock of Ethiopian Horro sheep. $\mathrm{PhD}$ thesis, University of the Free State, South Africa.

CSA (Central Statistical Agency) (2017). Agricultural sample survey, 2016/2017 (2009 EC). Report on livestock and livestock characteristics. Statistical Bulletin 585. Addis Ababa, Ethiopia: CSA.

ECRA (Ethiopian Customs and Revenue Authority) (2012). Raw data on the type, volume, value and destination of export items from Ethiopia. Addis Ababa, Ethiopia: ECRA (Ethiopian Customs and Revenue Authority).

FAO (Food and Agricultural Organization of the United Nations) (2012) FAO statistical database FAOStat. 2012. Rome, Italy: FAO. Retrieved from http://faostat3.fao.org/faostat-gateway/go/to/home/E

Gizaw, S., Abegaz, S., Abebe, A., Muluneh, D., \& Tesfay, Z. (2018). Livestock breeding strategy for Ethiopia: Small ruminant breeding strategy (2018-2030). Addis Ababa, Ethiopia: Ministry of Agriculture and Livestock.

Gizaw, S., Komen, H., \& van Arendonk, J. A. M. (2009). Optimal village breeding schemes under smallholder sheep farming systems. Livestock Science, 124, 82-88. https://doi.org/10.1016/j. livsci.2009.01.001

Gizaw, S., Komen, H., \& van Arendonk, J. A. M. (2010). Participatory definition of breeding objectives and selection indexes for sheep breeding in traditional systems. Livestock Science, 128, 67-74. https://doi.org/10.1016/j.livsci.2009.10.016

Gutu, Z., Haile, A., Rischkowsky, B., Mulema, A. A., Kinati, W., \& Tesfahun, G. (2015). Evaluation of community-based sheep breeding programs in Ethiopia. Addis Ababa, Ethiopia: ICARDA. hdl. handle.net/10568/76233.

Haile, A., Mirkena, T., Duguma, G., Gizaw, S., Wurzinger, M., Solkner, J., ... Rischkowsky, B. (2017) Community-based sheep breeding programs in Ethiopia resulted in substantial genetic gains. ISAG 2017 Abstract book. pp. 154-155. 36th international society for Animal Genetic Conference, 16th-21st July 2017, University College of Dublin, Ireland.

Haile, A., Wurzinger, M., Mueller, J. P., Mirkena, T., Duguma, G., Mwai, O., ...Rischkowsky, B. (2011). Guidelines for setting up community-based sheep breeding programs in Ethiopia. ICARDA tools and guidelines No.1, ICARDA, Aleppo, Syria.

ICAR-FAO (2000). Developing breeding strategies for lower input animal production environments. In S. Galal, J. Boyazoglu, \& K. Hammond (Eds.), Technical Series No. 3 (570 p.). Rome, Italy: ICAR and FAO.

Kebede, T., Haile, A., Dadi, H., \& Alemu, T. (2012). Genetic and phenotypic parameter estimates for reproduction traits in indigenous Arsi-Bale goats. Tropical Animal Health and Production, 44, 10071015. https://doi.org/10.1007/s11250-011-0034-8

Kosgey, I. S., \& Okeyo, A. M. (2007). Genetic improvement of small ruminants in low-input, smallholder production systems: Technical and infrastructural issues. Small Ruminant Research, 70, 76-88. https://doi.org/10.1016/j.smallrumres.2007.01.007

Legese, G., \& Fadiga, M. (2014) Small ruminant value chain development in Ethiopia: Situation analysis and trends. ICARDA/ ILRI Project Report. Nairobi, Kenya: International Center for Agricultural Research in the Dry Areas/International Livestock Research Institute.

Mueller, J. P., Rischkowsky, B., Haile, A., Getachew, T., \& Mourad, R. (2017). Outscaling community-based breeding programs in 
10

WI LEY - ${ }_{\text {Animal Breeding and Genetics }}^{\text {Douma }}$

HALE ET AL.

Ethiopia. Consultancy report (14 pp.). Addie Abeba, Ethiopia: ICARDA.

Mueller, J. P., Rischkowsky, B., Haile, A., Getachew, T., \& Mourad, R. (2018). Genetic progress and economic benefit of sheep communitybased breeding programs out- and up-scaling options in Ethiopia. Consultancy report (15 pp.). Adds Abeba, Ethiopia: ICARDA.

Mueller, J. P., Rischkowsky, B., Haile, A., Philipsson, J., Mwai, O., Besbes, B., ... Wurzinger, M. (2015). Community-based livestock breeding programmes: Essentials and examples. Journal of Animal Breeding and Genetics, 132, 155-168. https://doi.org/10.1111/ jog. 12136

NBE (National Bank of Ethiopia) (2018). Annual report 2017/2018. Addis Abaca, Ethiopia: NBE (National Bank of Ethiopia).

Shapiro, B. I., Gebru, G., Desta, S., Negassa, A., Nigussie, K., Aboset, G., \& Mechal, H. (2015). Ethiopia livestock master plan. ILRI Project Report. Nairobi, Kenya: International Livestock Research Institute (ILRI).

Sölkner, J., Nakimbigwe, H., \& Valle-Zarate, A. (1998) Analysis of determinants for success and failure of village breeding programs. In: Proceedings of the fth world congress on genetics applied to livestock production, 11-16 January 1998 (pp. 273-280). Armidale, NSW, Australia.
Tibbo, M. (2006). Productivity and health of indigenous sheep breeds and crossbred in the central Ethiopian highlands. $\mathrm{PhD}$ thesis, Swedish University of Agricultural Sciences. Uppsala, Sweden.

Tibbo, M., Iñiguez, L., \& Rischkowsky, B. (2008). Livestock and chimate change: local breeds, adaptation and ecosystem resilience. CARAVAN Issue 25, 37-39.

Yapi-Gnoare, C. V. (2000). The open nucleus breeding programme of the Djallonke sheep in Cote d'Ivoire. In S. Gall, J. Boyazoglu, \& K. Hammond (Eds.), Workshop on developing breeding strategies for lower input animal production environments, Bella, Italy, 22-25 September 1999. ICAR Technical Series 3 (pp. 283-292). Rome, Italy: International Committee for Animal Recording.

How to cite this article: Hails A, Gizaw S, Getachew $\mathrm{T}$, et al. Community-based breeding programmes are a viable solution for Ethiopian small ruminant genetic improvement but require public and private investments. J Anim Breed Genet. 2019;00:1-10. https://doi.org/10.1111/jbg.12401 